\title{
Work related stress and associated factors among Huajian shoe manufacturing employees in Dukem town, central Ethiopia
}

\author{
Morke Mezgebu Etefa ${ }^{1}$, Mulat Gebrehiwot Teklu² and Destaw Fetene Teshome ${ }^{3^{*}}$
}

\begin{abstract}
Objective: The objective of this study was to assess the prevalence of work-related stress (WRS) and its determinants among Huajian shoe manufacturing company employees in Dukem town, central Ethiopia. An institutional-based cross-sectional study was conducted from February to March 2016. Data were collected using pretested structured interviewer-administered questionnaires.

Results: The mean age of the participants, $56.2 \%$ of whom were male was 25 (SD \pm 5 ) years. The overall prevalence of work-related stress was $40.4 \%$ (95\% Cl 35.7, 45.3). Poor organizational support (adjusted odds ratio (AOR) 2.40, 95\% Cl 1.39, 4.77), inadequate work experience (AOR 3.77, 95\% Cl 1.68, 8.45), poor salary (AOR 7.04, 95\% Cl 3.39, 14.59), long working hours (AOR 3.40,95\% Cl 2.00, 5.79), overtime work (AOR 2.24, 95\% Cl 1.10, 4.61), and poor physical environment (AOR $2.44,95 \% \mathrm{Cl} 1.42,4.19$ ) were factors significantly associated with the stress. The prevalence of the stress was higher than what can be expected of many such employees. Poor organizational support, inadequate work experience, poor salary offers, long working hours, overtime work, and poor physical environment were significantly and independently associated with WRS. Establishing a functional collective agreement between employer and an employee trade union are needed to improve the problem.
\end{abstract}

Keywords: Work related stress, Shoe manufacturing employees, Ethiopia

\section{Introduction}

Work-related stress occurs when there is a mismatch between the demands of the job and the resources and capabilities of the individual worker to meet those demands $[1,2]$. Such stress is the second most reported work-related health problem next to musculoskeletal disorders [3-5]. The number of people suffering from stress-related conditions caused or made worse by work is increasing with an alarming rate and becoming an issue of public health concern in developing countries [6]. Globally, WRS accounts for 35\% of all work related illnesses [7]. Studies conducted in Bristol City, England [8], Vietnam [9], Indian resident doctors [10], Iran [11],

\footnotetext{
*Correspondence: destaw.fetene@gmail.com

${ }^{3}$ Department of Epidemiology and Biostatistics, Institute of Public Health, College of Medicine and Health Sciences, University of Gondar, Gondar, Ethiopia

Full list of author information is available at the end of the article
}

Tanzania [12], and Ethiopia [13] also show that one-inthree employees experience work-related stress.

Work-related stress is the major cause of occupational ill health which causes severe physical and psychological conditions resulting in poor productivity, human error, increased sick leaves, high staff turnover, and poor performance damaging the image of the organization both among workers and other stakeholders $[2,14]$.

According to research reports, some of the factors significantly associated with WRS include, over $50 \mathrm{~h}$ of work per week [15], long daily working hours [16], high work demands, time pressure, and too many administrative tasks [17].

Studies which primarily focused on the prevalence and associated factors in health care settings indicate that WRS is a major public health problem in developing countries. In Ethiopia, little is known about the magnitude and the determinants of the problem on the most at risk manufacturing industry workers. Therefore, this 
study aimed to assess work-related stress and its associated factors among Huajian shoe manufacturing employees in Dukem town, central Ethiopia. The information to be obtained is expected to increase the awareness of managers to prevent its occurrence, carryout early screening and detection of stress, and improve employee quality of life and organizational performance.

\section{Main text}

\section{Methods}

An institution based cross sectional study was conducted from February to March 2016, at Huajian Shoe Manufacturing Company, central Ethiopia. The company is located in Dukem town, $37 \mathrm{~km}$ southeast of Addis Ababa, the capital of Ethiopia. Owned by foreign investors, the company has around 4500 Ethiopian workers.

Employees currently engaged in the company and have worked for more than 6 months prior to the study were included in the study. Night shift workers during the study were excluded from the study. Sample size was determined using the single population proportion formula, assuming the proportion of work related stress to be $50 \%$, level of certainty $95 \%$, margin of error $5 \%$, and non-response rate of $10 \%$. The simple random sampling technique was used to select the 422 study participants.

A structured questionnaire was used to collect data on socio-demographic characteristics. Other previously validated tools employed for the purpose were the Work Place Stress Scale (WPSS) [18], the Job Content Questionnaire (JCQ) [19], and the National Institute for Occupational Safety and Health (NIOSH) [20]. These tools inquired about organizational factors (working conditions, job security, salary offer, experience in the current organization, working hours, organizational support, employee recognition, and overtime work), and job content factors (time pressure, job demand, job control, resources, opportunity to learn, interactions of people with machines, illness and physical environment).

To assess work-related stress, a 20-item standard questionnaire with a 5-point Likert scale was used. The scores ranged from 1 (Never) to 5 (Very often), and the reverse scores ranged from 5 (Never) to 1 (Very often) according to their perceived work place occurrence [13]. The results were summed for all WPSS questions, and a score below 60 was classified as having a work-related stress. Poor working conditions were considered when the summed scores of participants' were less than 10. Poor organizational support was considered when the summed scores of participants' were less than 7. High time pressure was defined as the summed scores of participants' were more than 10. Poor physical environment was defined as the summed score of participants scores were below 9 .
The questionnaires was initially prepared in English and translated to Affan Oromo (local language) and retranslated to English by language experts. Four health professionals and a supervisor participated in the data collection after two days intensive training. Data were checked for completeness, clarity, and consistency (Additional file 1).

The data entered using Epi Info version 7 and analyzed by SPSS version 20. Data were presented in the form of texts and tables. Bivariate logistic regression analysis was done and variables with $p$-values of up to 0.20 were included in the multivariable analysis to control possible effects of confounders. Variables which had significant associations with WRS were identified on the basis of OR with a $95 \% \mathrm{CI}$ and $\mathrm{p}$-values $<0.05$.

\section{Results}

A total of 406 participants were involved in the study with a response rate of $96 \%$. The mean age of the participants was $25(\mathrm{SD} \pm 5)$ years of whom $228(56.2 \%)$ were male. Two hundred eleven (52\%) were married; 214 (52.7\%) had above secondary school education; 162 (39.9\%) were Orthodox Christians, and 143 (35.2\%) earned Ethiopian Birr (ETB) $\leq 1100 /$ month (Table 1).

Of the participants, 234 (57.6\%) got poor support from their organization; $279(68.7 \%)$ worked in poor working conditions; 270 (66.5\%) believed there was job insecurity; 219 (53.9\%) got no recognition, and 211 (52\%) were poorly paid for their work.

Regarding working hours, $214(52.7 \%)$ of the participants worked $\leq 48 \mathrm{~h} /$ week, and 311 (76.6\%) worked overtime for more than $20 \mathrm{~h} /$ month. Two hundred forty-nine (61.3\%) and 261 (64.3\%) of the participants experienced high time pressure and high attention job demands relating to their jobs, respectively. Of the total participants, 392 (96.6\%) had poor learning opportunities; 104 (25\%) had poor interaction with their machines, and 209 (51.5\%) worked under a poor physical environment (Table 2).

The overall prevalence of work-related stress was $40.4 \%$ (95\% CI 35.7-45.3). The prevalence was higher, that is, $68.3 \%, 75 \%$, and $78 \%$ among employees who worked under poor working physical environment, poor organizational support, and poor salary offers, respectively.

The multivariable logistic regression analysis revealed that poor organizational support, poor salary offers, inadequate work experience, over working hours, overtime work, and poor physical environments were significantly associated with work related stress. Accordingly, the likelihood of developing WRS for employees with payments of ETB $\leq 1100$ ETB and between ETB 1101 and 1300 monthly were about six times (AOR 5.87, 
Table 1 Socio demographic characteristics of participants, Huajian shoe manufacturing, Dukem town, central Ethiopia, $2016(n=406)$

\begin{tabular}{|c|c|c|}
\hline Variables & Frequency & Percent \\
\hline \multicolumn{3}{|l|}{ Sex } \\
\hline Male & 228 & 56.2 \\
\hline Female & 178 & 43.8 \\
\hline \multicolumn{3}{|l|}{ Age } \\
\hline $18-21$ & 61 & 15.0 \\
\hline $22-26$ & 208 & 51.2 \\
\hline $27-30$ & 104 & 25.6 \\
\hline $31-34$ & 31 & 7.6 \\
\hline$\geq 35$ & 2 & 0.5 \\
\hline \multicolumn{3}{|l|}{ Marital status } \\
\hline Single & 186 & 45.8 \\
\hline Married & 211 & 52.0 \\
\hline Others $^{\mathrm{a}}$ & 9 & 2.2 \\
\hline \multicolumn{3}{|l|}{ Educational status } \\
\hline Primary school & 1 & 0.2 \\
\hline Secondary school & 191 & 47.1 \\
\hline Above secondary & 214 & 52.7 \\
\hline \multicolumn{3}{|l|}{ Religion } \\
\hline Orthodox & 162 & 39.9 \\
\hline Protestant & 152 & 37.4 \\
\hline Muslim & 71 & 17.5 \\
\hline Others $^{b}$ & 21 & 5.2 \\
\hline \multicolumn{3}{|c|}{ Monthly income $(E T B)^{c}$} \\
\hline$\leq 1100$ & 143 & 35.2 \\
\hline $1101-1300$ & 91 & 22.4 \\
\hline $1301-1450$ & 102 & 25.1 \\
\hline$>1450$ & 70 & 17.2 \\
\hline \multicolumn{3}{|l|}{ Type of employment } \\
\hline Permanent & 405 & 99.8 \\
\hline Temporary & 1 & 0.2 \\
\hline
\end{tabular}

a Divorce, widowed, separated

b Wakefeta, catholic

c Quartile classification

95\% CI 2.39, 14.42) and three times (AOR 3.02, 95\% CI $1.19,7.67)$ as those getting greater than ETB 1450, respectively.

Employees who worked under poor organizational support were two times (AOR 2.40, 95\% CI 1.39, 4.77) as likely to develop WRS as those working under good organizational support. Employees who reported poor salary offers were seven times (AOR 7.04, 95\% CI 3.39, 14.59 ) as likely to develop WRS as those with good salary offers. Employees who had 1.6-2.01 years of work experiences were about four times (AOR 3.77, 95\% CI $1.68,8.45$ ) as likely to have WRS as those with work experiences of greater than 2.09 years.
Table 2 Organizational and Job related characteristics of participants, Huajian shoe manufacturing, Dukem town, central Ethiopia, $2016(n=406)$

\begin{tabular}{|c|c|c|}
\hline Variables & Frequency & Percent \\
\hline \multicolumn{3}{|c|}{ Organizational support } \\
\hline Good & 172 & 42.4 \\
\hline Poor & 234 & 57.6 \\
\hline \multicolumn{3}{|l|}{ Working conditions } \\
\hline Good & 127 & 31.3 \\
\hline Poor & 279 & 68.7 \\
\hline \multicolumn{3}{|l|}{ Job security } \\
\hline Good & 136 & 33.5 \\
\hline Poor & 270 & 66.5 \\
\hline \multicolumn{3}{|c|}{ Employees'recognition } \\
\hline Good & 187 & 46.1 \\
\hline Poor & 219 & 53.9 \\
\hline \multicolumn{3}{|l|}{ Salary offers } \\
\hline Satisfied & 195 & 48.0 \\
\hline Dissatisfied/poor & 211 & 52.0 \\
\hline \multicolumn{3}{|c|}{ Work experience in the current organization in years ${ }^{a}$} \\
\hline $0.06-1.05$ & 113 & 27.8 \\
\hline $1.06-2.01$ & 102 & 25.1 \\
\hline $2.02-2.09$ & 91 & 22.4 \\
\hline$>2.09$ & 100 & 24.6 \\
\hline \multicolumn{3}{|c|}{ Working hours per week ${ }^{b}$} \\
\hline$\leq 48$ & 214 & 52.7 \\
\hline$>48$ & 192 & 47.3 \\
\hline \multicolumn{3}{|c|}{ Overtime working hours per month ${ }^{b}$} \\
\hline$\leq 20$ & 95 & 23.4 \\
\hline$>20$ & 311 & 76.6 \\
\hline \multicolumn{3}{|l|}{ Time pressure } \\
\hline High & 249 & 61.3 \\
\hline Low & 157 & 38.7 \\
\hline \multicolumn{3}{|c|}{ Job demand attention } \\
\hline High & 261 & 64.3 \\
\hline Low & 145 & 35.7 \\
\hline \multicolumn{3}{|l|}{ Illness } \\
\hline Yes & 355 & 87.4 \\
\hline No & 51 & 12.5 \\
\hline \multicolumn{3}{|l|}{ Job control } \\
\hline High & 359 & 88.4 \\
\hline Low & 47 & 11.6 \\
\hline \multicolumn{3}{|l|}{ Resource } \\
\hline Enough & 182 & 44.8 \\
\hline Scarcity & 224 & 55.2 \\
\hline \multicolumn{3}{|c|}{ Learning opportunity } \\
\hline Good & 14 & 3.4 \\
\hline Poor & 392 & 96.6 \\
\hline \multicolumn{3}{|c|}{ Interaction of people with machine } \\
\hline Good & 302 & 74.4 \\
\hline Poor & 104 & 25.4 \\
\hline \multicolumn{3}{|c|}{ Physical environment } \\
\hline Good & 197 & 48.5 \\
\hline Poor & 209 & 51.5 \\
\hline
\end{tabular}

${ }^{a}$ Quartile classification

b Based on Ethiopian labour proclamation 377/2003 
Table 3 Bivariate and multivariable logistic regression analysis of factors associated with Work related stress $(n=406)$

\begin{tabular}{llll}
\hline Variables & $\begin{array}{l}\text { Work } \\
\text { related } \\
\text { stress }\end{array}$ & COR $(95 \% \mathrm{Cl})$ & AOR $(95 \% \mathrm{Cl})$ \\
& $\frac{1}{\text { Yes No }}$ &
\end{tabular}

\begin{tabular}{|c|c|c|c|c|}
\hline \multicolumn{5}{|c|}{ Monthly income (ETB) } \\
\hline$\leq 1100$ & 86 & 57 & $7.29(3.60,14.80)$ & $5.87(2.39,14.42)^{*}$ \\
\hline $1101-1300$ & 39 & 52 & $3.63(1.70,7.70)$ & $3.02(1.19,7.67)^{*}$ \\
\hline $1301-1450$ & 27 & 75 & $1.74(0.81,3.73)$ & $1.13(0.45,2.89)$ \\
\hline$>1450$ & 12 & 58 & 1 & 1 \\
\hline \multicolumn{5}{|c|}{ Organizational support } \\
\hline Good & 41 & 131 & 1 & 1 \\
\hline Poor & 123 & 111 & $3.54(2.30,5.50)$ & $2.40(1.39,4.17)^{*}$ \\
\hline \multicolumn{5}{|l|}{ Salary offers } \\
\hline Satisfied & 36 & 159 & 1 & 1 \\
\hline Dissatisfied/poor & 128 & 83 & $6.81(4.32,10.74)$ & $7.04(3.39,14.59)^{*}$ \\
\hline \multicolumn{5}{|c|}{ Work experience in the current organization in years } \\
\hline $0.06-1.05$ & 61 & 52 & $5.34(2.85,10.04)$ & $1.99(0.90,4.39)$ \\
\hline $1.06-2.01$ & 54 & 48 & $5.13(2.69,9.73)$ & $3.77(1.68,8.45)^{*}$ \\
\hline $2.02-2.09$ & 31 & 60 & $2.35(1.21,4.59)$ & $1.65(0.72,3.74)$ \\
\hline$>2.09$ & 18 & 82 & 1 & 1 \\
\hline \multicolumn{5}{|c|}{ Working hours per week } \\
\hline$\leq 48$ & 55 & 227 & 1 & 1 \\
\hline$>48$ & 109 & 83 & $3.80(2.50,5.77)$ & $3.40(2.00,5.79)^{*}$ \\
\hline \multicolumn{5}{|c|}{ Overtime working hours per month } \\
\hline$\leq 20$ & 17 & 74 & 1 & 1 \\
\hline$>20$ & 147 & 164 & $4.11(2.31,7.27)$ & $2.24(1.10,4.61)^{*}$ \\
\hline \multicolumn{5}{|c|}{ Job demand attention } \\
\hline Low & 129 & 107 & 1 & 1 \\
\hline High & 126 & 135 & $2.63(1.69,4.09)$ & $0.50(0.24,1.06)$ \\
\hline \multicolumn{5}{|c|}{ Physical environment } \\
\hline Good & 52 & 145 & 1 & 1 \\
\hline Poor & 112 & 97 & $3.22(2.12,4.89)$ & $2.44(1.42,4.19)^{*}$ \\
\hline
\end{tabular}

* $p$-value $<0.05$; the Hosmer and Lemeshow test: 0.401

Employees who worked for more than 48 normal working hours per week were three times (AOR 3.40, 95\% CI $2.00,5.79)$ as likely to have WRS as those working for $48 \mathrm{~h}$ or less per week. Employees who reported more than 20 overtime working hours per month were two times (AOR 2.24, 95\% CI 1.10, 4.61) as likely to have work related stress as those working $20 \mathrm{~h}$ or less per month. Employees who worked under poor physical environments were two times (AOR 2.44, 95\% CI 1.42, 4.19) as likely to have a work related stress as those working in good physical environments (Table 3 ).

\section{Discussion}

Work stress is recognized world-wide as a major challenge to employees' health and the healthiness of their organizations. In this study, the overall prevalence of work-related stress was $40.4 \%$ (95\% CI 35.7, 45.3). The result was comparable with those of studies conducted at Addis Ababa public hospitals (37.8\%) [13] and West Sus$\operatorname{sex}(43 \%)$ [21].

However, it was higher than those of studies done in European countries (35\%) [7], Bristol City (20\%) [8], Vietnam (20.7\%) [9], India (32.8\%) [10], Iran (21.3\%) [11], and Tanzania (30.1\%) [12]. The difference may be explained by the fact that developed countries with their better socio-economic status have organized safety precautions and facilitated access to health and safety trainings ahead of time. They have also improved the levels of enforcement regulations on health service delivery better than developing countries [5].

In this study, associations were observed between work-related stress and different variables. For example, poor organizational support had a significant association with WRS. The finding was consistent with those of studies conducted in Nigeria [22] and Sweden [23], where the likelihood of work-related stress was higher among employees with poor organizational support. The reason could be that employees with inadequate support from their employers often suffer from frustration, apathy, and poor performance. This in turn leads to unsafe work practices, staff turnover rise and even illness [24].

Poor salary offers had a significant association withwork related stress in this study. The finding was similar with that of a study conducted in Iran [11]. The reason for poor payment might be the availability of cheap labour and low market competitions in the country. Working for poor payments could increase stress due to the inability of employees to meet monthly obligations (supporting themselves and their families) [25].

Employees who had between 1.06 and 2.01 years of work experience in the current organization had a significant association with work related stress. This is due to the fact that the interaction of people with machines in the first stage and getting new incur results stress on their work.

Working for more than 48 working hours per week had a significant association with work related stress. The finding was consistent with those of studies conducted in Saudi Arabia [15], Germany and Austria [16], and the USA [26]. This is perhaps due to the fact that long working hours without enough breaks to attend to other life matters lead to exhaustion and affect health 
by impairing employee's possibilities for sufficient recovery both mentally and physiologically $[27,28]$.

Working for more than 20 overtime working hours per month had a significant association with work related stress. The finding was supported by studies conducted in Tenibiaje Dele Joseph in Nigeria [4], Japanese workers [29], and in the United States [30] which stated that overtime work significantly increased the risk for work-related stress. This might be because overtime work prolongs high workload, interferes with leisure activities, causes too much employee physically and mentally fatigue to perform to the best of their ability, thereby increasing stress hormones [31].

Working under poor physical environments has a strong and independent role in increasing the likelihood of WRS. Consistent to what was reported from Ghana [32], Kerala [33], and Iran [34], this study revealed the likelihood of developing WRS was higher among employees who worked under poor physical environments. This is due to the fact that the elements of poor physical environments (unpleasant sound, extremely high or low temperature, poor air circulation, exposure to dangerous substances, smelling, and lighting) directly affect employee motivation and job performance adversely [35]. Such a persistent exposure to environmental stressors causes the immune system to be compromised; as a result, employees may have a more difficult time staying healthy and become stressed [36].

In conclusion, this study showed that a high proportion of employees had work-related stress. Poor organizational support, inadequate work experience, poor salary offers, over working hours, overtime work, and poor physical environment were significantly and positively associated with work-related stresses. Thus, employers need to attempt to update employee payments and implement reward evaluation systems, cut down the need for overtime or employ extra staff. Efforts should also be made to make the working environment conducive for workers and to minimize physical hazards that lead employees to work-related stress.

\section{Limitations}

Since the data was collected in day time, we didn't include night shift workers; this might have under estimated the proportion of the work-related stress.

\section{Additional file}

Additional file 1. WRS-Questionnaires. This is the English version of the questionnaires.
Abbreviations

AOR: adjusted odds ratio; ETB: Ethiopian Birr; JCQ: Job Content Questionnaire; $\mathrm{NIOSH}$ : National Institute for Occupational Safety and Health; OR: odds ratio; WPSS: Work Place Stress Scale; WRS: work-related stress.

\section{Authors' contributions}

All authors equally participated in the conception, design, analysis, and interpretation. MME facilitated the data collection and drafted the manuscript. DFT and MGT made critical revision of the manuscript for important intellectual content. All authors had full access to all of the data in the study and take responsibility for the integrity of the data and the accuracy of the data analysis. All authors read and approved the final manuscript.

\section{Author details}

${ }^{1}$ Dukem Town Administration Health Office, Oromia National Regional State, Dukem, Ethiopia. ${ }^{2}$ Department of Environmental and Occupational Sciences, Institute of Public Health, College of Medicine and Health Sciences, University of Gondar, Gondar, Ethiopia. ${ }^{3}$ Department of Epidemiology and Biostatistics, Institute of Public Health, College of Medicine and Health Sciences, University of Gondar, Gondar, Ethiopia.

\section{Acknowledgements}

We are indebted to the University of Gondar for permission to conduct the study. Our gratitude also goes to data collectors and supervisors participated in the study.

\section{Competing interests}

The authors declare that they have no competing interests.

\section{Availability of data and materials}

The minimal data underlying all the findings in the manuscript will be available upon request.

\section{Consent to publish}

Not applicable.

\section{Ethics approval and consent to participate}

Ethical approval was obtained from the Ethical Review committee of the Institute of Public Health, College of Medicine and Health Sciences, University of Gondar. Permission letter was secured from Huajian shoe manufacturing company Chief Executive Officer. Each study participant was informed about the purpose, method, expected benefit, and risk of the study. They were also informed about their right not to participate or stop the interview during interview. Since it is a cross-sectional study, participating in this study cannot result any negative consequences on the study participants. Hence, an informed verbal consent obtained from each study participant, and participant involvement in the study was voluntary. Confidentiality of data was guaranteed by using identification numbers rather than names and limiting access to the data.

Funding

Not applicable.

\section{Publisher's Note}

Springer Nature remains neutral with regard to jurisdictional claims in published maps and institutional affiliations.

Received: 18 June 2018 Accepted: 21 August 2018

Published online: 24 August 2018

\section{References}

1. Blaug R, Kenyon A, Lekhi R. Stress at work: Aa report prepared for the work foundation's principal partners. London: The Work Foundation; 2007.

2. Work-Related Stress Guidelines. Occupational Safety and Health Division. Ministry of Labour: Ministry of Labour, Industrial Relations, Employment and Training; 2016. 
3. Milczarek M, Schneider E, Rial González E. OSH in figures: stress at workfacts and figures. European Risk Observatory Report. Luxembourg: Office for Official Publications of the European Communities: European Agency for Safety and Health at Work; 2009.

4. Joseph TD. Work related stress. Eur J Bus Soc Sci. 2013;1(10):73-80.

5. World Day for Safety and Health at Work 2013. 28 April 2013.

6. Houtman I, Jettinghof K, Cedillo L, World Health Organisation. Raising awareness of stress at work in developing countries: a modern hazard in a traditional working environment: advice to employers and worker representatives. Geneva: World Health Organisation; 2007.

7. Buckley P. Work related stress, anxiety and depression statistics in Great Britain. London: Health and Safety Executive; 2015.

8. Smith A, Johal S, Wadsworth E, Smith GD, Peters T. The scale of occupational stress: the Bristol stress and health at work study. Sudbury: HSE Books; 2000.

9. Minh KP. Work-related depression and associated factors in a shoe manufacturing factory in Haiphong City, Vietnam. Int J Occu Med Environ Health. 2014;27(6):950-8.

10. Saini N, Agrawal S, Bhasin S, Bhatia M, Sharma A. Prevalence of stress among resident doctors working in Medical Colleges of Delhi. Indian J Public Health. 2010;54(4):219.

11. Soori H, Rahimi M, Mohseni H. Occupational stress and work-related unintentional injuries among Iranian car manufacturing workers. East Mediterr Health J. 2008;14:697-703.

12. Mkumbo K. Prevalence of and factors associated with work stress in academia in Tanzania. Int J Higher Educ. 2014;3(1):1-11.

13. Salilih SZ, Abajobir AA. Work-related stress and associated factors among nurses working in public hospitals of Addis Ababa, Ethiopia: a crosssectional study. Workplace Health Saf. 2014;62(8):326-32.

14. Tackling work-related stress using the management standards approach. In: Health and Safety Executive; 2017

15. Salam A, Abu-Helalah M, Jorissen SL, Niaz K, Mansour A, Qarni AA. Job stress and job satisfaction among health care professionals. Eur Sci J. 2014;10(32):1857-7881.

16. Sehlen S, Vordermark D, Schäfer C, Herschbach P, Bayerl A, Pigorsch S, Rittweger J, Dormin C, Bölling T, Wypior HJ. Job stress and job satisfaction of physicians, radiographers, nurses and physicists working in radiotherapy: a multicenter analysis by the DEGRO Quality of Life Work Group. Radiat Oncol. 2009;4(1):6

17. Tabaj A, Pastirk S, Bitenc Č , Masten R. Work-related stress, burnout, compassion, and work satisfaction of professional workers in vocational rehabilitation. Rehabil Counsel Bull. 2015;58(2):113-23.

18. Attitudes in the American Workplace VII. The workplace stress scale. Yonkers: Marlin Company and the American Institute of Stress; 2009.

19. Karasek R, Brisson C, Kawakami N, Houtman I, Bongers P, Amick B. The Job Content Questionnaire (JCQ): an instrument for internationally comparative assessments of psychosocial job characteristics. J Occup Health Psychol. 1998;3(4):322.
20. NIOSH Generic Job Stress Questionnaire, vol. 513. Cincinnati, OH 45226: National Institute for Occupational Safety and Health; 2011. p. 533-8165.

21. Phillips S, Sen D, McNamee R. Prevalence and causes of self-reported work-related stress in head teachers. Occup Med. 2007;57(5):367-76.

22. Arogundade TO, Arogundade BA, Adebajo O. The influence of perceived organizational support on job stress among selected public and private sector employees in Lagos state, Nigeria. Adv Res. 2015:3(6):541-7.

23. Holmgren K, Dahlin-Ivanoff S, Björkelund C, Hensing G. The prevalence of work-related stress, and its association with self-perceived health and sick-leave, in a population of employed Swedish women. BMC Public Health. 2009;9(1):73.

24. Tucker-McLaughlin M. The importance of dealing With organizational stress.

25. Mayhew R. How can low wages affect employees in an organization? September 26, 2017.

26. Persaud H, Williams S. Long working hours and occupational stressrelated illness and injury: mini review. J Health Sci Educ. 2017;1:115.

27. Bell J: Long working hours and stress are leading to health problems, doctors warn. In.; September 11, 2016

28. Seth $D$, Singh $N$. Adverse health consequences-a result of long work hours: a review of the current evidence. Indian J Nutr. 2016;3:125.

29. Sato Y, Miyake $H$, Thériault $G$. Overtime work and stress response in a group of Japanese workers. Occup Med. 2008;59(1):14-9.

30. Dembe AE, Erickson JB, Delbos RG, Banks SM. The impact of overtime and long work hours on occupational injuries and illnesses: new evidence from the United States. Occup Environ Med. 2005;62(9):588-97.

31. Dahlgren A. Work stress and overtime work: effects on cortisol, sleep, sleepiness and health. Stockholm: Stockholm University; 2006.

32. Agyemang CB, Nyanyofio JG, Gyamfi GD. Job stress, sector of work, and shift-work pattern as correlates of worker health and safety: a study of a manufacturing company in Ghana. Int J Bus Manag. 2014;9(7):59.

33. Areekkuzhiyil S. Factors influencing the organizational stress among teachers working in higher education sector in kerala: an empirical analysis. Res Pedagog Interv. 2014;2:1-15.

34. Dianat I, Salimi A. Working conditions of Iranian hand-sewn shoe workers and associations with musculoskeletal symptoms. Ergonomics. 2014;57(4):602-11.

35. Vischer JC. The effects of the physical environment on job performance: towards a theoretical model of workspace stress. Stress Health. 2007;23(3):175-84.

36. Adomaitis MB. Environmental stressors in the workplace. 2006-2018. https://stress.lovetoknow.com/Definition_of_Work_Stress. Accessed 23 Aug 2018.

\footnotetext{
Ready to submit your research? Choose BMC and benefit from:

- fast, convenient online submission

- thorough peer review by experienced researchers in your field

- rapid publication on acceptance

- support for research data, including large and complex data types

- gold Open Access which fosters wider collaboration and increased citations

- maximum visibility for your research: over 100M website views per year
}

At BMC, research is always in progress.

Learn more biomedcentral.com/submissions 